\title{
BIOASSOCIATIVE EFFECT OF RHIZOSPHERIC MICROORGANISMS ON GROWTH, NUTRIENT UPTAKE AND YIELD OF MUNG BEAN (VIGNA RADIATA L. WILCZEK)
}

\author{
NISHA KADIAN, KULDEEP YADAV, and ASHOK AGGARWAL*
}

Department of Botany, Kurukshetra University, Kurukshetra-136119

*Corresponding author: aggarwal_vibha@rediffmail.com

\section{ABSTRACT}

Nitrogen applications have generated great interests in agriculture, with much of its success associated with increasing the uptake of nitrogen by crops while reducing pollution by this chemical fertilizer. The aim of the present study was to evaluate the interactive effect of rhizospheric microorganisms on nutrient uptake, yield and growth of mung bean grown in pots under glasshouse conditions. The results revealed that the growth, in terms of morphology and physiology, of all the inoculated plants was better than that of the control plants. In terms of growth, plant height, fresh and dry weights and length of the roots plants inoculated with both Funneliformis mosseae $+T$. viride did best. Total chlorophyll content, alkaline and acidic phosphatase activities were greatest when inoculated with only $F$. mosseae and fresh and dry weights of shoots when inoculated only with T. viride. Significant increase in N and P uptake was recorded when inoculated with both $F$. mosseae $+T$. viride. Overall the significant increase in growth and development was due to positive interactions among rhizospheric microorganisms leading to healthy and vigorously growing plants. However, there is now a need for field trails of this technique.

Keywords: Arbuscular mycorrhizal fungi, nutrient uptake, phosphatase activity, nitrogen fixing bacteria, Trichoderma viride, mung bean

\section{Introduction}

Legumes are important land plants as they are able to grow in water-deficient and low-nutrient environments. Many legumes form symbiosis with both nitrogen fixing rhizobia and arbuscular mycorrhizal (AM) fungi. Dual inoculation with both microorganisms results in a tripartite mutualistic symbiosis and increases plant growth to a greater extent than inoculation with only one of them (Chalk et al. 2006). Vigna radiata (L.) Wilczek commonly known as mung bean is an important grain legume crop in South East Asia and Africa, and a source food that has a high nutritive value (Kumar et al. 2002; Salunke et al. 2005). It is not only a rich and economical source of protein, phosphorus, carbohydrate, minerals and provitamin A, but also commonly used as fodder and green manure. Mung bean contains bioactive components with antioxidant, antimicrobial and insecticidal properties (Bounce 2002; Kaprelynts et al. 2003; Madhujith et al. 2004; Ahmad et al. 2008).

The scarcity of food containing high levels of protein, micronutrients and various vitamins sources is an increasing problem affecting millions of people in developing countries (Burchi et al. 2011). The need for innovative technologies to meet the growing challenges of scarcity of food and malnutrition in the poor and hungry parts of the world must be addressed (Clugston 2002). To improve the quality and yield of economically important legumes, particularly mung bean, farmers apply large quantities of chemical fertilizer, which has detrimental effects on the soil, such as the accumulation of toxic salts. Application of environmentally friendly and potentially cost effective microbial bio-fertilizer could be a better solution (Mia and Shamsuddin 2010).

Structural and physiological studies have revealed that legumes form tripartite symbiotic associations with nodule forming rhizobia and AM fungi (Barea et al. 2005). The micro-symbionts in both associations are benefited by photo assimilates from the plant. The macro-symbionts fix nitrogen in the case of the bacterial symbiosis in root nodules (Brewin 1991; Crespi and Galvez 2000) and immobile nutrients, especially phosphate, in the case of AM symbiosis (Stract et al. 2003; Miransari et al. 2009). Nitrogen availability and P uptake from less soluble sources is an important issue, thus it is important to understand the tripartite association of legumes with Rhizobium and AM (Kwapata and Hall 1985; Satter et al. 2006). There is increasing evidence that diverse microbial populations in the rhizosphere play a significant role in agricultural sustainability (Barea et al. 2002). However, due to the obligatory biotrophy of AM fungi, the two symbioses are rarely studied together. Moreover, the initiation and functioning of the tripartite symbiosis is complex and despite efforts made over the last two decades or so, there are still many facts about this symbiosis that are unknown (Gianinazzi-Pearson et al. 1995). Considering the beneficial effect of AMF on other crops, more attention should be paid to combining appropriate mycorrhizal fungi with other soil microbes in order to increase yields of mung bean. With this in mind, a pot experiment was carried out under glass house conditions to investigate the effect of AM fungi alone or in combination with other bio-inoculants on mung bean. 


\section{Material and methods}

\section{Mass multiplication of bio-inoculants}

The two dominant AM species used in this study were Funneliformis mosseae (T.H. Nicolson and Gerd.) Walker and Schüßler and Acaulospora laevis Gerdemann and Trappe. These species were isolated from the rhizosphere of mung beans collected from the Botanical Garden, $\mathrm{Ku}$ rukshetra University, Kurukshetra and kept in sterilized polythene bags at $10^{\circ} \mathrm{C}$ for further processing. The AM species were propagated in association with barley under standard pot culture conditions. The culture of Rhizobium sp. (procured from Department of Microbiology, CCS Haryana Agricultural University, India) was mass multiplied using nutrient broth medium and that of T. viride on a modified wheat bran-saw dust medium (Mukhopadhyay et al. 1986).

\section{Preparation of pot mixture}

The experiment was laid out in a randomized complete block design, with five replicates of each treatment. Top soil $(0-30 \mathrm{~cm})$ was collected from the Botanical garden of Botany Department, Kurukshetra University, Kurukshetra, which consisted of $20.8 \%$ silt, $3.78 \%$ clay, and had a $\mathrm{pH}$ of $8.05,0.0485$ total $\mathrm{N}$ and $0.015 \%$ available $\mathrm{P}$. This soil was air dried and passed through a $2 \mathrm{~mm}$ sieve. The soil to be used in the experiment consisted of a soil: sand mixture $(3: 1, \mathrm{v} / \mathrm{v})$, which had been autoclaved for 20 minutes at $121{ }^{\circ} \mathrm{C}$ and 15 psi. Each pot was filled with the sterilized soil:sand mixture to which $10 \%$ (w/w of soil) of the selected AM inoculum was added. T. viride inoculum containing $3.4 \times 10^{8} \mathrm{cfu} \mathrm{gm}^{-1}$ was added as per the treatment. The seeds were surface sterilized with $10 \%$ solution of sodium hypochlorite for 1-2 minutes and then washed thoroughly with distilled water. Before sowing seeds $10 \mathrm{ml}$ of a liquid suspension of bacteria, with a density $10^{8} \mathrm{cells} / \mathrm{ml}$, was applied to each pot. Pots were watered once every two days, and fertilized with a nutrient solution after 15 days (Weaver and Fredrick 1982), which contained half the recommended level of phosphorus and no nitrogen. Pots were either treated with a single inoculum, a combined inoculum or no inoculum as outlined below:

1. Uninoculated i.e. autoclaved sterile sand: soil with no inoculum (control 1)

2. Uninoculated i.e. unsterilized sand: soil with no inoculum (control 2)

3. Funneliformis mosseae (F)

4. Acaulospora laevis (A)

5. Trichoderma viride $(\mathrm{T})$

6. $\mathrm{F}+\mathrm{T}$

7. $\mathrm{A}+\mathrm{T}$

8. $\mathrm{F}+\mathrm{A}$

9. $\mathrm{F}+\mathrm{A}+\mathrm{T}$

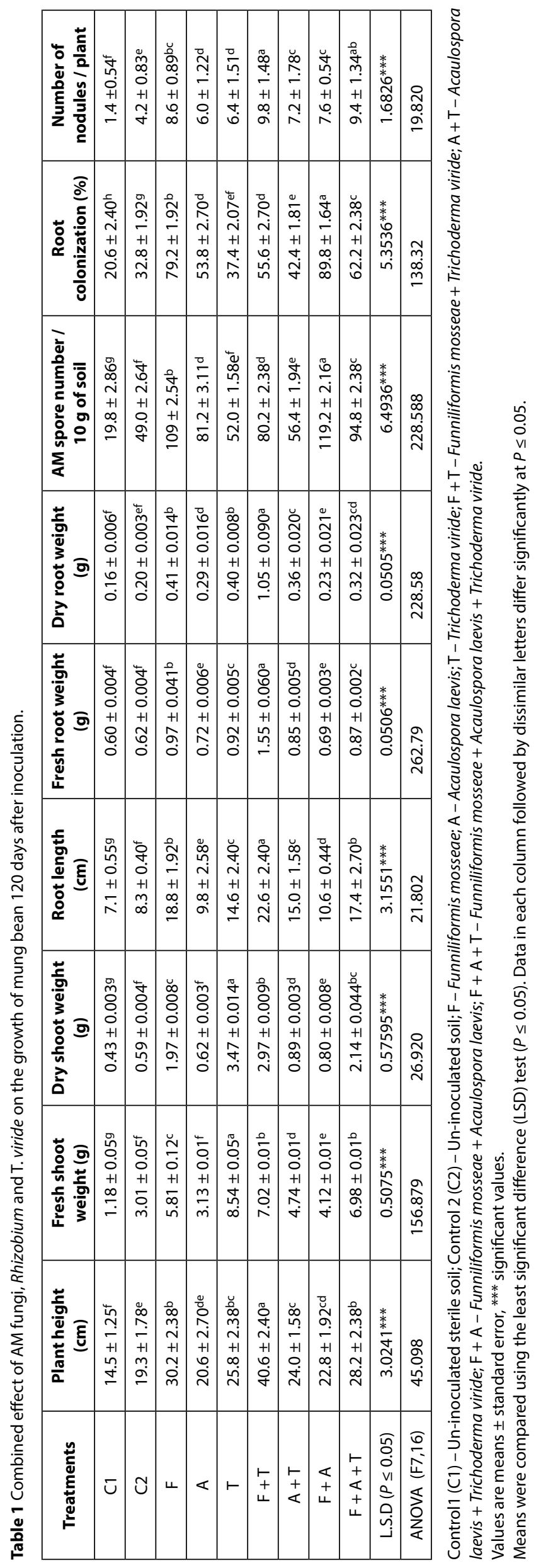




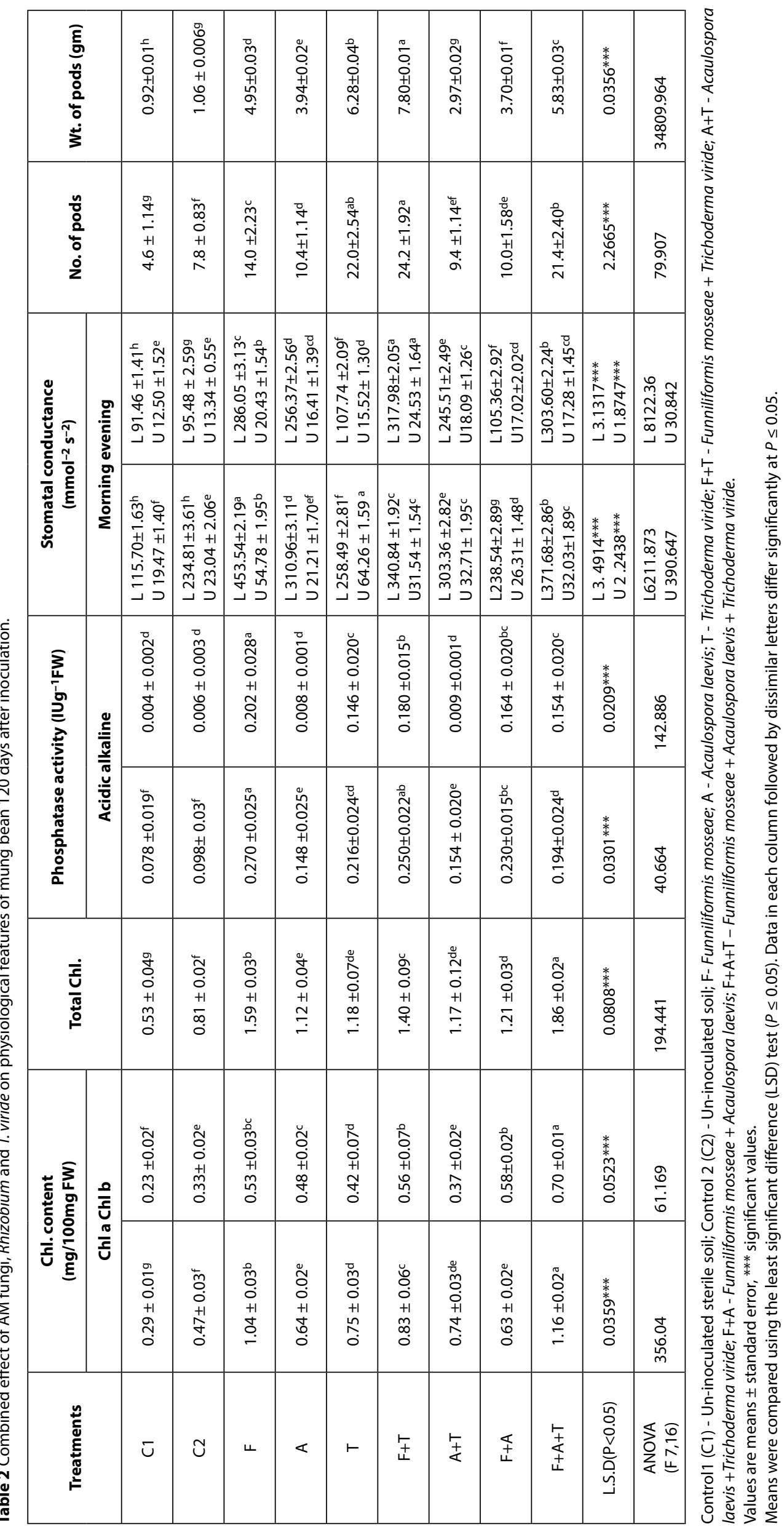




\section{Plant harvest, growth and nutrient analysis}

Plants were harvested after 120 days by uprooting them from the soil and various morphological and physiological features measured. For determining root and shoot fresh and dry weight, roots and shoots were harvested after 120 days, weighed and then, oven dried at $70^{\circ} \mathrm{C}$ and weighed again. Amount of chlorophyll a, chlorophyll b and total chlorophyll was estimated using the method of Arnon (1949). Stomatal conductance $\left(\mathrm{mmol}^{-2} \mathrm{sec}^{-2}\right)$ was measured using a Porometer $\left(\mathrm{AP}_{4}\right.$-DELTA-T DEVICESCambridge-U.K.). Phosphorus concentration were determined using the 'Vanado-molybdo-phosphoric yellow colour method' (Jackson 1973) and Nitrogen using the Kjeldahl method. Phosphatase activity was assayed using p-nitrophenyl phosphate (PNPP) as a substrate, which is hydrolyzed by the enzyme to $\mathrm{p}$-nitrophenol (Tabatabi and Bremner 1969).

\section{Identification and quantification of the number and colonization by AM spores}

AM spores (F. mosseae and A. laevis) were identified by using the identification manual used by Walker (1983), Scheneck and Perez (1990), Morton and Benny (1990) and Mukerji (1996). Quantification of the number of AM spores was done using the Adholeya and Gaur 'Grid Line Intersect Method' (1994). Mycorrhizal colonization of roots was determined using the 'Rapid Clearing and Staining Method' of Phillips and Hayman (1970). Percentage AM colonization of roots was: (Number of root segments colonized / number of root segments studied) $\times 100$.

\section{Statistical analysis}

Data were subjected to analysis of variance and means separated using the least significant difference test in the Statistical Package for Social Sciences (ver.11.5, Chicago, IL, USA).

\section{Results}

It is evident from (Table 1) that inoculated plants were taller than the un-inoculated control plants. The increase in plant height was significantly greatest for those inoculated with both $F$. mosseae $+T$. viride followed by those inoculated only with $F$. mosseae. This indicates that mung bean benefited from the particular mycorrhizal symbioses used in this study.

Maximum increment in shoot biomass was recorded in single inoculation treatment with T. viride followed by dual inoculation with F. mosseae and T. viride. According to the results in Table 1 root biomass (fresh and dry) was also significantly greater in all the treatments than the control. After 120 days, the increase in root biomass was greatest in the dual treatment with $F$. mosseae and $T$. viride followed by that in the single treatment with F. mosseae.
The greatest root length was recorded for plants inoculated with both F. mosseae and T. viride followed by those inoculated only with F. mosseae.

The result indicates that the mycorrhizal colonization of roots and number of spores of AM recorded for the treated plants varied (Table 1). The maximum number of spores and percentage colonization of roots was recorded for plants treated with F. mosseae + A. laevis and $T$. viride and then those treated with a single inoculation of $F$. mosseae.

Chlorophyll content of all the treated plants was greater than that of the control. According to Table 2 the highest increment in total chlorophyll content was recorded for plants treated with F. mosseae + A. laevis + T. viride and then those treated with a single inoculation of G. mosseae.

According to Table 2 the phosphatase activity recorded for inoculated plants was considerably greater than that recorded for the control. This is due to the mycorrhizal fungal hyphae that secrete acid and alkaline phosphatases (APA and ALA) into the rhizosphere. The acidic phosphatase activity was greatest for the F. mosseae treated plants followed by those treated with F. mosseae $+T$. viride. In addition, the greatest alkaline activity was recorded for the treatment with F. mosseae. Acidic phosphatase activity was greater than that of alkaline phosphatase.

Mycorrhizal colonization of roots also influences the behaviour of the stomata of the leaves. Stomatal conductance (morning and evening) of plants treated with different combinations of AM fungi and T. viride increased (Table 2). Stomatal conductance was greatest in the morning in plants treated with $F$. mosseae and in the evening in those treated with F. mosseae $+T$. viride. The conductance recorded for the stomata on the lower surface of leaves was greater in the morning than the evening.

The maximum number of nodules was recorded for the dual inoculation treatment, i.e. with F. mosseae and T. viride, followed by the triple inoculation treatment with $F$. mosseae, A. laevis and T. viride. The inoculation of several different microbes appears to result in a synergistic interaction among them that substantially improves the nutrition available to the mung bean plants.

AM fungi improved the mineral nutrition of associated plants (Table 3). Mung bean plants inoculated with AM fungi and T. viride had increased $\mathrm{N}$ and $\mathrm{P}$ contents in roots and shoots compared with the control. Among all the treated plants those inoculated with $F$. mosseae showed the greatest percentage increase in shoot and root $\mathrm{P}$ content and those treated with both $F$. mosseae + A. laevis the greatest percentage in shoot and root $\mathrm{N}$. This might be due to an increase in carbon supplied by the plant to the AM fungi, which increases the uptake and transfer of nutrients from fungi to plants. In the present study, more $\mathrm{P}$ than $\mathrm{N}$ was absorbed by all the $\mathrm{AM}$ inoculated mung bean plants. The increase in P content was 
due to the AM fungal network that can take up $\mathrm{P}$ and convert it into polyphosphate granules in the extra radical hyphae and pass it to the arbuscules, which then make it available to plants. The increase in total $\mathrm{N}$ is attributed to the increased $\mathrm{N}_{2}$ fixation by the AM hyphae.

Data on yield (Table 2) indicate that bioinoculation of mung bean plants with either AM or T. viride resulted in a significant increase in the weight of the pods and consequently higher yields compared to the control. Treatment with a mixture of $F$. mosseae and T. viride resulted in the greatest increase in yield in terms of the number of pods followed by those plants treated with T. viride. That is, the greatest yield was of plants inoculated with both AM fungi and T. viride, which operated together more effectively in supplying their host plants with their nutrient requirements than when either operated on its own.

\section{Discussion}

In the present investigation, dual inoculation or a mixed inoculation gave better results than either of the two inoculates on their own. The $\mathrm{F}+\mathrm{T}$ treatment gave better results than the other treatments because Trichoderma might produce extra cellular metabolites that enhance the AM population in the soil. The increased height of mycorrhizal plants is attributed to a higher AM colonization, which is known to enhance plant growth by increasing nutrient uptake and plant growth promoting substances in the rhizosphere of mung bean. The beneficial effects of AM symbiosis are also known to be mediated by phytohormones, which could be suitable candidates for signaling between plants and AM fungi and important in the auto regulation of mycorrhization (Meixner et al. 2005). These observations accord with earlier reports of Nzanza et al. (2011) that Solanum lycopersicum inoculated with Trichoderma harzianum and AM fungi are taller than control plants. Vázquez et al. (2000) also found that inoculation with AM and other microbes resulted in taller maize plants. The better results obtained when unsterilized rather than sterilized soil is used may be due to the presence of natural micro-flora in the soil. This may be due to competition for space and nutrition between the diverse microflora in unsterilized soil.

Khan et al. (2008) also report a significant increase in shoot and root dry weight of Medicago sativa following inoculation with AM fungi. Similar results are also reported by Arumugam et al. (2010) for Vigna unguiculata inoculated with AM and Rhizobium. This may be due to the fact that there were no indigenous microbes to compete with the inoculated strain. Secondly, the greater reproduction of AM fungi in soil based inoculums, which sprouted rapidly from extracellular and intracellular hyphae, absorbsed more nutrients, even far from the surface of the roots, which enhanced the growth and biomass of the plants.

The better results obtained when only $F$. mosseae was inoculated may be due to better space and nutrition for its multiplication and survival in sterilized soil, and therefore it was able to absorb more nutrients from the soil resulting a better growth of mung bean. In addition, the mycorrhizal colonization of the soil in effect enabled the plants' root systems to extend deeper into the soil and invade nutrient depleted zones and enhance soil aggregation, which ultimately improves the access of the root system to soil water and nutrients. Galleguillos et

Table 3 Combined effect of AM fungi, Rhizobium and T. viride on the nitrogen and phosphorus content of mung bean 120 days after inoculation.

\begin{tabular}{|c|c|c|c|c|}
\hline \multirow{3}{*}{$\begin{array}{c}\text { Treatments } \\
\mathrm{C} 1\end{array}$} & \multirow{2}{*}{\multicolumn{2}{|c|}{ Phosphorus content (\%) }} & \multicolumn{2}{|c|}{ Nitrogen content (\%) } \\
\hline & Shoot Root & & \multicolumn{2}{|c|}{ Shoot Root } \\
\hline & $0.05 \pm 0.024^{f}$ & $0.21 \pm 0.022^{\mathrm{e}}$ & $1.03 \pm 0.022^{9}$ & $0.40 \pm 0.024^{f}$ \\
\hline C2 & $0.16 \pm 0.01 \mathrm{e}$ & $0.22 \pm 0.01$ de & $1.34 \pm 0.025^{f}$ & $0.51 \pm 0.016^{\mathrm{e}}$ \\
\hline $\mathrm{F}$ & $0.30 \pm 0.028^{\mathrm{a}}$ & $0.36 \pm 0.024^{a}$ & $1.62 \pm 0.022^{\mathrm{a}}$ & $0.67 \pm 0.020^{b}$ \\
\hline A & $0.22 \pm 0.023 c$ & $0.27 \pm 0.017 c$ & $1.41 \pm 0.028^{\mathrm{de}}$ & $0.54 \pm 0.023^{d}$ \\
\hline $\mathrm{T}$ & $0.21 \pm 0.016^{c}$ & $0.25 \pm 0.025^{c d}$ & $1.40 \pm 0.015^{\mathrm{e}}$ & $0.53 \pm 0.028^{\mathrm{de}}$ \\
\hline$F+T$ & $0.29 \pm 0.019 \mathrm{ab}$ & $0.35 \pm 0.028^{a b}$ & $1.55 \pm 0.019^{b}$ & $0.64 \pm 0.020^{b}$ \\
\hline$A+T$ & $0.19 \pm 0.019^{d}$ & $0.23 \pm 0.020 \mathrm{de}^{\mathrm{s}}$ & $1.43 \pm 0.023^{d}$ & $0.56 \pm 0.020^{c d}$ \\
\hline $\mathrm{F}+\mathrm{A}$ & $0.26 \pm 0.031^{b}$ & $0.33 \pm 0.022^{b}$ & $1.64 \pm 0.027^{\mathrm{a}}$ & $0.74 \pm 0.019^{a}$ \\
\hline$F+A+T$ & $0.20 \pm 0.024^{d}$ & $0.32 \pm 0.020^{b}$ & $1.52 \pm 0.031^{c}$ & $0.58 \pm 0.020^{c}$ \\
\hline L.S.D $(P<0.05)$ & $0.0317^{* * *}$ & $0.0295^{* * *}$ & $0.0314^{* * *}$ & $0.0282^{* * *}$ \\
\hline $\begin{array}{c}\text { ANOVA } \\
(\mathrm{F} 7,16)\end{array}$ & 41.182 & 32.305 & 282.229 & 102.191 \\
\hline
\end{tabular}

Control1 (C1) - Un-inoculated sterile soil; Control 2 (C2) - Un-inoculated soil; F - Funniliformis mosseae; A - Acaulospora laevis; T - Trichoderma viride; $\mathrm{F}+\mathrm{T}-$ Funniliformis mosseae + Trichoderma viride; $\mathrm{A}+\mathrm{T}-$ Acaulospora laevis + Trichoderma viride; $\mathrm{F}+\mathrm{A}-$ Funniliformis mosseae + Acaulospora laevis; $\mathrm{F}+\mathrm{A}+\mathrm{T}-$ Funniliformis mosseae + Acaulospora laevis + Trichoderma viride.

Values are means \pm standard error, ${ }^{* * *}$ significant values.

Means were compared using the least significant difference (LSD) test $(P \leq 0.05)$. Data in each column followed by dissimilar letters differ significantly at $P \leq 0.05$. 
al. (2000) record a significant increase in root length of plants inoculated with G. mosseae and Chen et al. (2006) that of Trifolium repens and Coreopsis drummondii growing in soil inoculated with an isolate of $G$. mosseae.

The mixed inoculum of $\mathrm{F}+\mathrm{A}+\mathrm{T}$ gave better results than the control, which may be due to their synergistic effect. Since the spatial distribution of soil hyphae can vary among fungal species, an increase in the overall hyphal density of AM mycelium around the roots resulting from colonization by several AM fungi may be greater than colonizations by a single species. Alternately, different AM fungi may produce different amounts of soil binding agents and the interactions of these agents within the aggregates may result in a synergistic effect on soil stability. Rhizobium species are also effective root colonizers as they produce secondary metabolites that enhance AMF growth and thus increase mycorrhizal spore number and colonization of mung bean. In addition, $T$. viride may behave as a mycorrhizal helper by promoting higher percentage colonization and AM spore number. The results of the present investigation are in agreement with the findings of Hemashenpagam and Selvaraj (2011) as Solanum viarum was also inoculated with AM fungus and plant growth promoting rhizobacteria (PGPR's).

The increase in chlorophyll content recorded in the present investigation may be due to an increase in stomatal conductance, photosynthesis, transpiration and enhanced plant growth. Increase in chlorophyll content in mycorrhizal treated plants indicates an increase in the rate of photosynthesis, which can be ascribed to an increase in the absorption of nutrients. This supports the hypothesis that soil micro-organisms produce phytohormones and a number of extra-cellular enzymes, which decompose the complex organic matter before it is absorbed as a source of energy, which stimulate plant growth (Richard et al. 2007). Several workers report more chlorophyll in the leaves of mycorrhizal plants than those of non-mycorrhizal plants (Karthikeyan et al. 2009; Arumugam et al. 2010).

The activity of acid phosphatase may be associated with the growth and development of the fungus within the tissue of the host and with phosphorus acquisition by the rhizosphere. In the present investigation, it was found that phosphatase activity (alkaline and acidic) in plants was greatest in those with the greatest mycorrhizal root colonization. Alkaline phosphatase activity is also closely linked with both the stimulation of mycorrhizal growth and arbuscular phase of the colonization. Studies have revealed that alkaline phosphatase activity is localized in the vacuoles of mature arbuscules (Gianiniazzi et al. 1979). These enzymes (APA and ALA) help in mineralization of bound phosphorus into a soluble form, which makes it more easily available to plants. The present findings are in agreement with numerous other reports (Dodd et al. 1987; Rubio et al. 1990; Abdel-Fattah 2001). Thus, phosphatase activity may be helpful in improving soil health and also act as an indicator of soil quality.
The progressive increase in stomatal conductance resulting from $\mathrm{AM}$ inoculation might be due to higher rates of photosynthesis and increase in the number of stomata on the lower surfaces of the leaves. Higher rates of stomatal conductance in mycorrhizal plants are also reported by Auge (2001). Fidelbus et al. (2001) also report that AM fungi have positive role in lowering the rate of leaf conductivity of citrus seedlings growing in very dry soils.

The greater number of nodules number of treated plants may be due to the mutual positive action of Rhizobium species and AM fungi strains in increasing the uptake of phosphorus and nitrogen from soil. The role of arbuscular mycorrhizae in improving nodulation and $\mathrm{N}_{2}$ fixation is universally recognized. AM fungi are known to release an unidentified diffusional factor (myc factor) (Parniske 2008; Maillet et al. 2011), which activates the nodulation factor's inducible gene, involved in establishing the symbiosis with the nitrogen fixing rhizobial bacteria (Kosuta et al. 2003). It is also reported that effective mycorrhizal colonization can also increase nodulation and symbiotic nitrogen fixation in legumes (Hamel 2004). Moreover, when Rhizobium bacteria are present in the soil, mycorrhizal colonization is increased due to an increase in the concentration of chemical signals involved in the establishment of symbiosis (Hirsch and Kapulnik 1998).

The AM prompted nutrient uptake may be due to an increase in surface area of soil contact, increased movement of nutrients into mycorrhizae, a modification of the root environment and increased storage. The effect of the mycorrhizal infection of the host plant is an increase in the uptake of $\mathrm{P}$, which is mainly due to the capacity of the mycorrhizal fungi to absorb phosphate from soil and transfer it to the host roots. Khan et al. (2008) also found an increase in both $\mathrm{N}$ and $\mathrm{P}$ followed by higher yield in Medicago sativa inoculated with Gigaspora rosea and Glomus intraradices. In addition, Safapour et al. (2011), report similar increases in yield of three varieties of red bean when inoculated with AM fungi and Rhizobium sp.

\section{Conclusions}

In conclusion, dominant arbuscular mycorrhizal fungi, either alone or in combination, can establish a symbiosis with mung bean, which results in this plant growing better and producing more beans under laboratory conditions. There is now a need to determine whether this technique can be used for increasing the growth and yield of mung bean under field conditions.

\section{REFERENCES}

Abdel-Fattah Gamal M (2001) Measurement of the viability of arbuscular-mycorrhizal fungi using three different stains; relation 
to growth and metabolic activities of soybean plants. Microbiol Res 156: 359-367.

Ahmad MSA, Hussain M, Ijaz S, Alvi AK (2008) Photosynthetic performance of two mung bean (Vigna radiata (L.) cultivars under lead and copper stress. Int J Agri Biol 10: 167-172.

Arumugam R, Rajasekaran S, Nagarajan SM (2010) Response of Arbuscular and Rhizobium inoculation on growth and chlorophyll content of Vigna unguiculata (L) Walp Var. Pusa 151. J Appl Sci Environ Manage 14: 113-115.

Auge RM (2001) Water relations, drought and vesicular arbuscular mycorrhizal symbiosis. Mycorrhiza 11: 3-42.

Barea JM, Azcon R, Azcon-Aguilar C (2002) Mycorrhizosphere interactions to improve plant fitness and soil quality. Antonie van Leeuwenhoek 81: 343-351.

Barea JM, Werner D, Azco'n-Guilar C, Azco'n R (2005) Interactions of arbuscular mycorrhiza and nitrogen-fixing symbiosis in sustainable agriculture. In: Werner D, Newton WE (eds) Nitrogen fixation in agriculture, forestry, ecology and the environment, 4th ed. Springer, Netherlands, pp. 199-222.

Bolan NS (1991) A critical review on the role of mycorrhizal fungi in the uptake of phosphorus by plants. Plant Soil 134: 189-207.

Brewin NJ (1991) Development of the legume root nodule. Ann Rev Cell Biol 7: 191-226.

Brounce F (2002) Soya is flavones: a new and promising ingredient for the health foods sector. Food Res 35: 187-193.

Burchi F, Fanzo J, Frison E (2011) The role of food and nutrition system approaches in tackling hidden hunger. Int J Environ ResPublic Health 8: 358-373.

Chalk PM, Souza R de F, Urquiaga S, Alves BJR, Boddey RM (2006) The role of arbuscular mycorrhiza in legume symbiotic performance. Soil Biol Biochem 38: 2944-2951.

Chen BD, Zhu YG, Duan J, Xiao XY, Smith SE (2006) Effects of the arbuscular mycorrhizal fungus Glomus mosseae on growth and metal uptake by four plant species in copper mine tailings. Elsevier Ltd, pp. 374-380.

Clugston GA (2002) Global nutrition problems and novel foods. Asian Pacific J Clinic Nutr 11: 100-111.

Crespi M, Galvez S (2000) Molecular mechanisms in root nodule development. J Plant Growth Regul 19: 155-166.

Dodd JC, Burton CC, Burns RG, Jeffries P (1987) Phosphatase Activity associated with the root and the rhizosphere of plants infected with Vesicular-Arbuscular Mycorrhizal Fungi. New Phytol 107: 163-172.

Fidelbous MW, Martin CA, Stutz JC (2001) Geographic isolates of Glomus increase root growth and whole plant transpiration of citrus seedlings growth with high phosphorus. Mycorrhiza 10: 231-236.

Galleguillos C, Aguirre C, Barea JM, Azcon R (2000) Growth promoting effect of two Sinorhizobium meliloti strains (a wild type and its genetically modified derivative) on a non-legume plant species in specific interaction with two arbuscular mycorrhizal fungi. Plant Science 159: 57-63.

Gianinazzi S, Gianinazzi-Pearson V, Gollotte A, Lherminier J, Tisserant B, Franken P, Dumas-Gaudot E, Lemoine MC, Tunimen DV, Gianinnazzi S (1995) Cellular and molecular approaches in the characterization of symbiotic events in functional arbuscular mycorrhizal associations. Can J Botany 73: 526-532.

Gianinazzi S, Gianinazzi-Pearson V, Dexheimer J. (1979). Enzymatic studies on the metabolism of vesicular-arbuscular mycorrhiza. III. Ultrastructural localization of acid and alkaline phosphatase in onion roots infected by Glomus mosseae (Nicol. And Gerd.). New Phytol 82: 127-132.

Hamel C (2004) Impact of arbuscular mycorrhiza fungi on $\mathrm{N}$ and P cycling in the root zone. Can J Soil Sci 84: 383-395.
Hemashenpagam N, Selvaraj T (2011) Effect of arbuscular mycorrhizal (AM) fungus and plant growth promoting rhizomicroorganisms (PGPR's) on medicinal plant Solanum viarum seedlings. J Environ Biol 32: 579-583.

Hirsch AM, Kapulnik Y (1998) Signal transduction pathways in mycorrhizal associations: Comparisons with the Rhizobium-Legume Symbiosis. Fungal Gen and Biol 23: 205-212.

Jackson ML (1973) Soil Chemical Analysis Prentice Hall, New Delhi.

Kaprelynts LV, Kisilev SV, Iorgachova EG (2003) Soybean isoflavones and prospects of their therapeutic application. Voprosy Pitaniya 72: 36-41.

Karthikeyan B, Joe MM, Jaleel CA (2009) Response of some medicinal plants to vesicular arbuscular mycorrhizal inoculations. J Sci Res 1: 381-386.

Khan A, Ayub N, Mirza SN, Nizami SM, Azam M (2008) Synergistic effect of dual inoculation (VAM) on the growth and nutrient uptake of Medicago sativa. Pak J Bot 40: 939-945.

Kosuta S, Chabaud M, Lougnon G, Gough C, Denarie J, Barker DG, Becard G (2003) A diffusible factor from arbuscular mycorrhizal fungi induces symbiosis-specific MtENOD11 expression in roots of Medicago truncatula. Plant Physiol 131: 952-962.

Kumar SV, Tan SG, Quah SC, Yusoff K (2002) Isolation and characterization of seven tetranucleotide microsatellite loci in mungbean, Vigna radiata. Mol Ecol Notes 2: 293-295.

Kwapata MB, Hall AE (1985) Effect of moisture regime and phosphorus on mycorrhizal infection, nutrient uptake and growth of cowpeas (Vigna unquiculata L.). Field Crop Res 12: 241-250.

Madhujith T, Naczk M, Shahidi F (2004) Antioxidant activity of common beans (Phaseolus vulgaris L.). J Food Lipids 11: 220-233.

Maillet F, Poinsot V, André O, Puech-Pagés V, Haouy A, Gueunier M, Cromer L, Giraudet D, Formey D, Niebel, A, Martinez EA, Driguez H, Bécard G, Dénarié J (2011) Fungal lipochitooligosaccharide symbiotic signals in arbuscular mycorrhiza. Nature 469: 58-63.

Mexiner C, Ludwig-Muller J, Miersch O, Gresshoff P, Staehlin C, Vierheilig H (2005). Lack of mycorrhizal autoregulation and phytohormonal changes in the supernodulating soybean mutants 1007. Planta 222: 709-715.

Mia MAB, Shamsuddin ZH (2010) Rhizobium as a crop enhancer and biofertilizer for increased cereal production. Afr J Biotechnol 9: 6001-6009.

Miransari M, Bahrami HA, Rejali F, Malakouti MJ (2009) Effects of soil compaction and arbuscular mycorrhiza on corn (Zea mays L.) nutrient uptake. Soil Tillage Res 103: 282-290.

Morton JB, Benny GL (1990) Revised classification of arbuscular mycorrhizal fungi (Zygomycetes): A new order, Glomales, two new suborders, Glomineae and Gigasporineae, with an emendation of Glomaceae. Mycotaxon 37: 471-491.

Mukerji KG (1996) Taxonomy of endomycorrhizal fungi. In: Mukerji KG, Mathur B, Chamola BP, Chitralekha P (eds) Advances in Botany. APH Pub. Co. New Delhi, pp. 211-221.

Mukhopadhyaya NB, Rahmbhat A, Patel GJ (1986) Trichoderma harzianum - a potential biocontrol agent for tobacco damping off. Tobacco Research 12: 26-35.

Nzanza B, Marai D, Soundy P (2011) Tomato (Solanum lycopersicum L.) seedling growth and development as influenced by Trichoderma harzianum and arbuscular mycorrhizal fungi. African J Microbiol Res 5: 425-431.

Parniske M (2008) Arbuscular mycorrhiza: the mother of plant root endosymbioses. Nat Rev Microbiol 6: 763-775. 
Phillips JM, Hayman DS (1970) Improved procedures for clearing roots and staining parasitic and VAM fungi for rapid assessment of infection. Trans Brit Mycol Soc 55: 158-161.

Richards CL, Carstens BC, Knowles LL (2007) Distribution modelling and statistical phylogeography: an integrative framework for generating and testing alternative biogeographical hypotheses. J Biogeography 34: 1833-1845.

Rubio R, Moraga E, Borie F (1990) Acid phosphatase activity and vesicular-arbuscular mycorrhizal infection associated with roots of 4 wheat cultivars. J Plant Nutr 13: 585-598.

Safapour,M, Ardakani M, Khaghani S, Rejali F, Zargari K, Changizi M, Teimuri M (2011) Response of Yield and Yield Components of Three Red Bean (Phaseolus vulgaris L) Genotypes to Co-Inoculation with Glomus intraradices and Rhizobium phaseoli. American-Eurasian J Agric Environ Sci 11: 398-405.

Salunke BK, Kotkar HM, Mendki PS, Upasani SM, Maheshwari VL (2005) Efficacy of flavonoids in controlling Callosobruchus chinensis (L.) (Coleoptera: Bruchidae), a post-harvest pest of grain legumes. Crop Prot 24: 888-893.

Satter MA, Hanafi MM, Mahmud TMM, Azizah H (2006) Influence of arbuscular mycorrhiza and source of phosphorus on root development and nodulation of Acaciamangi- um seedlings on degraded soils. Bangladesh. J Microbiol 23: 102-106.

Schenck NC, Perez Y (1990) Manual for the identification of VA mycorrhizal VAM fungi. University of Florida Press, Florida, USA.

Stract DTF, Hause B, Schiliemann W, Walter MH (2003) Arbuscular mycorrhiza: biological, chemical and molecular aspect. J Chem Ecol 29: 1955-1979.

Tabatabai MA, Bremner JM (1969) Use of p-nitrophenyl phosphate for assay of soil phosphatase activity. Soil Biol Biochem 1: 301-307.

Vazquez M, Cesar S, Azcon R, Barea Jose M (2000) Interactions between arbuscular mycorrhizal fungi and other microbial inoculants (Azospirillum, Pseudomonas, Trichoderma) and their effects on microbial population and enzyme activities in the rhizosphere of maize plants. Applied Soil Eco 15: 261-272.

Walker C (1983) Taxonomic concepts in the Endogonaceae spore wall characteristics in species description. Mycotaxon 18: 443-445.

Weaver RW, Fredrick LR (1982) Rhizobium In: Methods of soil analysis. Part 2. Chemical and microbiological properties. Agronomy monograph, No. 9. 2nd ed. Am Soc Agron Madison, Wis, pp. 1043-1070. 